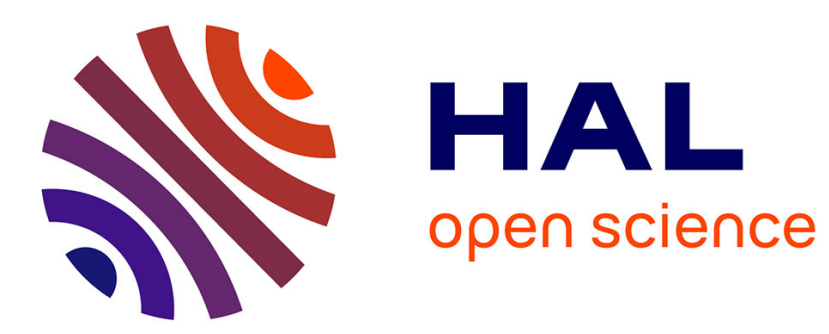

\title{
Interest of storage based STATCOM systems to the power quality enhancement of thyristors based LCC HVDC links for offshore wind farm
}

Heythem Hamlaoui, Bruno François

\section{- To cite this version:}

Heythem Hamlaoui, Bruno François. Interest of storage based STATCOM systems to the power quality enhancement of thyristors based LCC HVDC links for offshore wind farm. 2018 IEEE International Conference on Industrial Technology (ICIT), Feb 2018, Lyon, France. 10.1109/ICIT.2018.8352438 . hal-01918174

\author{
HAL Id: hal-01918174 \\ https://hal.science/hal-01918174
}

Submitted on 10 Nov 2018

HAL is a multi-disciplinary open access archive for the deposit and dissemination of scientific research documents, whether they are published or not. The documents may come from teaching and research institutions in France or abroad, or from public or private research centers.
L'archive ouverte pluridisciplinaire HAL, est destinée au dépôt et à la diffusion de documents scientifiques de niveau recherche, publiés ou non, émanant des établissements d'enseignement et de recherche français ou étrangers, des laboratoires publics ou privés. 


\section{Interest of storage based STATCOM systems to the power quality enhancement of thyristors based LCC HVDC links for offshore wind farm}

\author{
Heythem HAMLAOUI \\ Univ. Lille, Centrale Lille, Arts et Metiers Paristech, HEI, EA \\ 2697 - L2EP, Laboratoire d'Electrotechnique et d'Electronique de \\ Puissance, F-59000 Lille, France \\ heythem.hamlaoui@etudiant.univ-lille1.fr
}

\begin{abstract}
This paper defines a three level 48 pulse STATCOM based on GTO-VSC which is used to support the integration of remote large offshore wind farms into the main onshore grid using line-commutated high-voltage de connection (LCC-HVDC). This mature transmission technology requires a large quantity of reactive power. In order to enhance the dynamic performance of the LCC-HVDC connected to a weak system, this work presents STATCOM applications to improve the power quality and to avoid commutation failures. Simulation results show that HVDC LCC technology connected to a weak system needs extra reactive power compensation. It confirms the STATCOM performance and its dynamic and fast reactive power compensation during voltage fault conditions. Finally, the sizing of the STATCOM dc capacitor is studied.

Keywords-Power Quality, Offshore wind farm, HVDC, Line commutated converters (LCC), STATCOM.
\end{abstract}

\section{INTRODUCTION}

Facing the $\mathrm{CO}_{2}$ emission and global warming problems, the European Union (EU) encourages the integration of renewable energy in the power system. By 2020, up to $12 \%$ of the world's electricity are predicted to be provided by wind power [1]. Offshore wind farms have attracted attention since the wind power is abundant and installations have less visual impact.

For high sized wind farms and for long-distance connection between the offshore and onshore stations, HVDC transmission is more efficient than high-voltag1e ac (HVAC) connections [2], [3]. Compared with the VSC-HVDC [12], the LCC-HVDC is the most used one in industrial projects due to its high capacity, low cost and low power losses [4].

The main drawbacks of LCC-HVDC system are the high reactive power consumption, the bad power quality in both sides of the converter, the generation of low order harmonic and its sensibility to weak AC power systems. As the thyristor commutations depend on the zero-crossing of the alternating line voltage, any disturbance in the AC voltage will lead to a commutation failure. For that reason capacitor banks and filters are used for reactive power compensation and for harmonic mitigation to smooth the waveforms. However, the reactive power supply with only passive compensation (fixed capacitors) can be critical for weak systems and they will not supply sufficient reactive power during fault at the point of common connection (PCC). In order to improve the performance of LCC HVDC when it is connected to a weak AC system, a STATCOM

\author{
B. FRANCOIS \\ Univ. Lille, Centrale Lille, Arts et Metiers Paristech, HEI, EA \\ 2697 - L2EP, Laboratoire d'Electrotechnique et d'Electronique de \\ Puissance, F-59000 Lille, France \\ Bruno.francois@centralelille.fr
}

is used to enhance the power quality of voltages by generating or absorbing reactive power needed during steady-state and dynamic operation, providing the necessary sine voltage for the LCC operation.

The objective of this work is to consider a STATCOM application in order to ensure dynamic fast reactive power compensation at the PCC under transient conditions. The first part deals with the LCC-HVDC connection to a weak AC system and the different difficulties that will hinder the appropriate operation of this system. The next point will discusses the mathematical modeling of the STATCOM, its principle of working and the proposed control. After that, the system architecture will be presented and followed by the simulation results and discussion of both cases: with and without using a STATCOM. Finally, the paper discuss the impact of the STATCOM and its sizing to tackle the power quality issues in order to mitigate the harmonics and improve the dynamic performance.

\section{LCC-HVDC CONVERTERS CONNECTED TO A WEAK AC SYSTEM}

The operation of LCC-HVDC in a power system depends on the strength of the AC system [4]. A small disturbance in a weak system can affect the AC voltage waveform and causes commutation failure of the thyristor valves. This strength is characterized in term of the Short-Circuit Ratio (SCR) [5] between the short circuit capacity in MVA of the AC system $S_{s c}$, compared to the converter rated DC power $\mathrm{P}_{\mathrm{dc}}$ :

$$
S C R=\frac{S_{S c}}{P_{d c}}
$$

With $S_{s c}=\frac{V_{1}^{2}}{z_{t h}} ; V_{1}$ is the rated AC line voltage (fig. 1 ), $\mathrm{Z}_{\mathrm{th}}$ is the Thevenin impedance.

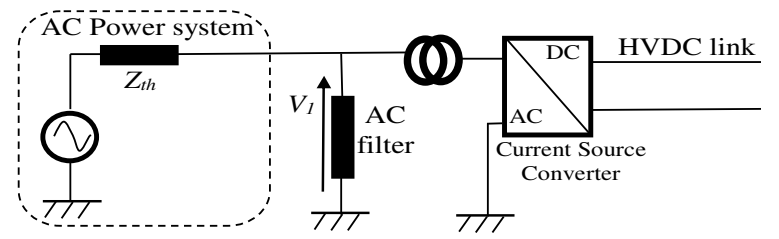

Fig. 1. Equivalent single phase circuit 
For a strong system $S C R$ is inferior to 3, weak systems have a $S C R$ between 3 and 2, whereas very weak systems have $S C R<2$ [6]. If a weak offshore wind farm AC system is connected to the LCC converter, operating problems may appear such as [6]: 1) Voltage instability, 2) Commutation failures of thyristor, 3) Harmonic resonances, 4) Temporary overvoltage. The recovery from commutation failures especially with weak AC systems requires a high reactive power.

\section{STATIC SYNCHRONOUS COMPENSATOR}

\section{A. Operation of a STATCOM}

Figure (2.a) shows a simplified electrical circuit of the STATCOM connected to the power system, where $X$ represents the leakage inductance of the coupling transformer, $V_{c}$ is the ac output voltage of the converter and $V_{s}$ is the line voltage.

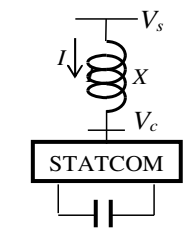

(a) Equivalent single phase circuit

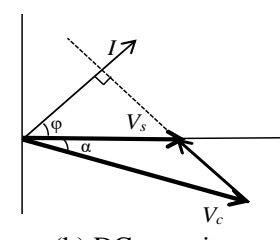

(b) DC capacitor charging

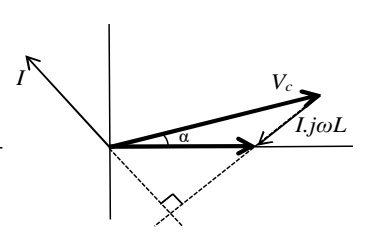

(c) DC capacitor discharging
Fig. 2. STATCOM operating characteristics

As shown in fig. 2.b, the phasor diagram represents the case when the phase difference $\alpha$ between $V_{s}$ and $V_{c}$ is negative. The line current will take direction in such way that an active power flows toward the converter and charges the dc capacitor. As conclusion, the rms value of the modulated output voltage $V_{c}$ is generated indirectly by charging or discharging a DC capacitor to a different voltage level. Therefore, increasing or decreasing the magnitude of the converter voltage causes the reactive power delivered to the AC bus to rise or fall.

According to hypothesis in [7], the three inductors are identical, the system is balanced, the resistance of each coil is negligible, compared to its inductance impedance. From the phasor diagram (figure 2.b), we obtain:

$$
\overrightarrow{V_{c}}=\overrightarrow{V_{S}}-\vec{\imath} . \mathrm{j} \omega L
$$

The projections on axis lead to:

$$
\begin{gathered}
V_{c} \cos \alpha=V_{s}+I \omega \mathrm{L} \cos \left(\frac{\pi}{2}-\varphi\right)=V_{s}-\omega \mathrm{L} I \sin \varphi \\
V_{c} \sin \alpha=I \omega L \sin \left(\frac{\pi}{2}-\varphi\right)=\omega L I \cos \varphi
\end{gathered}
$$

The active power is given by:

$$
P=3 V_{S} I \cos \varphi=3 V_{S} \frac{V_{c} \sin \alpha}{\omega L}
$$

In a same way the reactive power (exchanged with the grid) is given by:

$$
Q=3 V_{S} I \sin \varphi=3 V_{S} \frac{\left(V_{S}-V_{c} \cos \alpha\right)}{\omega L}
$$

Hence, the STATCOM may generate or consume reactive power according to $V_{c}$. By forcing the output voltage $V_{c}$ to lag the voltage of the AC system $\left(V_{s}\right)$ by a small angle, the converter absorbs a small amount of active power from the grid to recover the losses of power electronics devices and the transformer inductance.

\section{B. Mathematical modeling of the STATCOM}

As the voltage level is high, topologies of STATCOMs are based on series connection of single elements (semiconductors, bridges, ...) and so many multilevel topologies may be considered [11]. The equivalent circuit of a STATCOM consists of a DC link capacitor (working as an energy storage device), a voltage source converter (VSC) and the coupling transformer between the VSC bridge circuits and AC system (fig. 3).

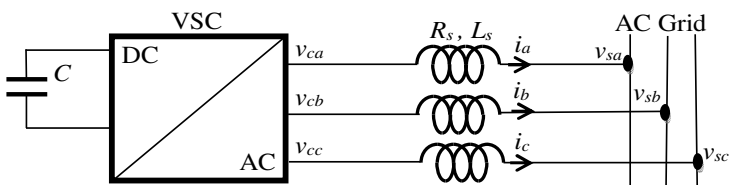

Fig. 3. Equivalent circuit of the studied STATCOM

$v_{s a}, v_{s b}, v_{s c}$ are voltages at the PCC. $v_{c a}, v_{c b}, v_{c c}$ are inverter output voltages. $L_{s}$ is the transformer leakage inductor. $R_{S}$ represents the inverter and transformer conduction losses. $\mathrm{C}$ is the DC equivalent capacitor. The grid voltages are assumed to be balanced and sinusoidal, no losses and no harmonics are assumed in the AC and DC power circuits. The relationship between the PCC voltages, the inverter output voltages and currents are obtained by writing the Kirchhoff equations for the figure 3 [8]:

$$
\begin{aligned}
& L_{s} \frac{d i_{a}}{d t}+R_{s} i_{a}(t)=v_{c a}(t)-v_{s a}(t) \\
& L_{s} \frac{d i_{b}}{d t}+R_{s} i_{b}(t)=v_{c b}(t)-v_{s b}(t) \\
& L_{s} \frac{d i_{c}}{d t}+R_{s} i_{c}(t)=v_{c c}(t)-v_{s c}(t)
\end{aligned}
$$

Equations (7) to (9) can be written in a matrix form as:

$$
\frac{d}{d t}\left[\begin{array}{l}
i_{a} \\
i_{b} \\
i_{c}
\end{array}\right]=\left[\begin{array}{ccc}
-\frac{R_{s}}{L_{s}} & 0 & 0 \\
0 & -\frac{R_{s}}{L_{s}} & 0 \\
0 & 0 & -\frac{R_{s}}{L_{s}}
\end{array}\right]\left[\begin{array}{c}
i_{a}(t) \\
i_{b}(t) \\
i_{c}(t)
\end{array}\right]+\frac{1}{L_{s}}\left[\begin{array}{c}
v_{c a}(t)-v_{s a}(t) \\
v_{c b}(t)-v_{s b}(t) \\
v_{c c}(t)-v_{s c}(t)
\end{array}\right]
$$

The Park's transformation is used to transform equation from the abc frame to a synchronous dq0 reference frame:

$$
\frac{d}{d t}\left[\begin{array}{l}
i_{d} \\
i_{q}
\end{array}\right]=\left[\begin{array}{cc}
-\frac{R_{s}}{L_{s}} & \omega \\
-\omega & -\frac{R_{s}}{L_{s}}
\end{array}\right]\left[\begin{array}{l}
i_{d}(t) \\
i_{q}(t)
\end{array}\right]+\frac{1}{L_{s}}\left[\begin{array}{l}
v_{c d}(t)-v_{s d}(t) \\
v_{c q}(t)+v_{s q}(t)
\end{array}\right]
$$

$\omega=2 \pi f$ is the system angular frequency of ac voltages. We can write a pair of equations for $\mathrm{v}_{c d}(\mathrm{t})$ and $v_{c q}(t)$ :

$$
\begin{aligned}
& v_{c q}(t)=m(t) \cdot v_{d c}(\mathrm{t}) \cdot \sin (\alpha) \\
& v_{c d}(t)=m(t) \cdot v_{d c}(\mathrm{t}) \cdot \cos (\alpha)
\end{aligned}
$$

$m$ is the modulation index of the inverter. $\alpha$ is the angle between the grid voltages and inverter output voltages, and it is the control input. According to the power balance theory, the 
instantaneous power at the AC terminals of the inverter is equal to the instantaneous power at the DC terminals of the inverter:

$$
v_{d c}(t) i_{d c}(t)=\frac{3}{2}\left(v_{c d}(t) i_{d}(t)+v_{c q}(t) i_{q}(t)\right)
$$

By combining previous equations, the current in the DC side of the STATCOM is expressed as:

$$
i_{d c}(t)=\frac{3}{2} m(t)\left(i_{d}(t) \cos \alpha+i_{q}(t) \sin \alpha\right)=C \frac{d V_{d c}}{d t}
$$

If the synchronous rotating frame is oriented such that $v_{s q}=0$, then we get:

$$
\frac{d}{d t}\left[\begin{array}{c}
i_{d} \\
i_{q} \\
v_{d c}
\end{array}\right]=A\left[\begin{array}{c}
i_{d}(t) \\
i_{q}(t) \\
v_{d c}(t)
\end{array}\right]-\frac{1}{L_{s}}\left[\begin{array}{c}
v_{s d}(t) \\
0 \\
0
\end{array}\right]
$$

Where $A$ is given by:

$$
A=\left[\begin{array}{ccc}
-\frac{R_{s}}{L_{s}} & \omega & -\frac{m(t)}{L_{s}} \cos (\alpha) \\
-\omega & -\frac{R_{s}}{L_{s}} & \frac{m(t)}{L_{s}} \sin (\alpha) \\
\left(-\frac{3}{2}\right)\left(\frac{m(t)}{C}\right) \cos (\alpha) & -\left(\frac{3}{2}\right)\left(\frac{m(t)}{C}\right) \sin (\alpha) & 0
\end{array}\right]
$$

According to [8], in a steady state, it can be noticed that $i_{d 0}$ is very small compared to $i_{q 0}$, which means there is nearly zero active power generated by the STATCOM. As $i_{q 0}$ varies, the angle $\alpha_{0}$ will change linearly, which means $i_{q 0}$ has an effect on the angle $i_{q 0}$. The instantaneous active and reactive powers are expressed as:

$$
\begin{gathered}
P=\frac{3}{2}\left(v_{d}(t) i_{d}(t)+v_{q}(t) i_{q}(t)\right)=\frac{3}{2} v_{d}(t) i_{d}(t) \\
Q=\frac{3}{2}\left(v_{q}(t) i_{d}(t)-v_{d}(t) i_{q}(t)\right)=-\frac{3}{2} v_{d}(t) i_{q}(t)
\end{gathered}
$$

By observing the right hand side of previous equations, the grid voltage is controlled by exchanging reactive power between STATCOM and power network. As $i_{d}$ is nearly equal to 0 , there is no real power exchange.

\section{Proposed control}

The goal is to control the AC voltage at the PCC by generating or consuming the appropriate $\mathrm{AC}$ current $\left(i_{q}\right)$ and so managing the required reactive power (eq. 17). The control scheme is illustrated in fig. 4 , the main blocks are:

- A Phase Locked Loop (PLL) is used to synchronize GTO pulses so that the AC generated voltages will be in phase with the network voltages.

- AC Voltage and current regulation: This structure consists of two PI controllers: the outer voltage control loop and the inner current control loop. The outer voltage loop computes the reference reactive current $\left(I_{q}^{*}\right)$, which will be used by the current regulator block. $\left(I_{q}^{*}\right)$ is obtained by controlling the error signal between the reference voltage $\left(v^{*}\right)$ to the magnitude of the line voltage $\left(\mathrm{V}_{s d q}\right)$. The inner control loop determines $\boldsymbol{\alpha}$ (which is the phase shift between the voltage inverter and the voltage system) and in turn generates gating pulse, the value of $\left(I_{q}\right)$ is compared with $\left(I_{q}^{*}\right)$ and the error signal is controlled to generate the angle $\boldsymbol{\alpha}$.

- For balancing the two DC capacitor voltages (that are used to create the total capacitor $C$ in fig. 3), the difference between voltages $\left(V_{d c 1}\right.$ and $\left.V_{d c 2}\right)$ is sensed and processed by a PI controller to introduce a phase shift $\Delta \boldsymbol{\alpha}$, which will be added to the main phase conduction angle variation $\boldsymbol{\alpha}$. The obtained angle $(\boldsymbol{\alpha}+\Delta \boldsymbol{\alpha})$ will be used to generate the triggering pulses for GTO-VSC units.

- Firing angle generator creates pulses for the four inverters.

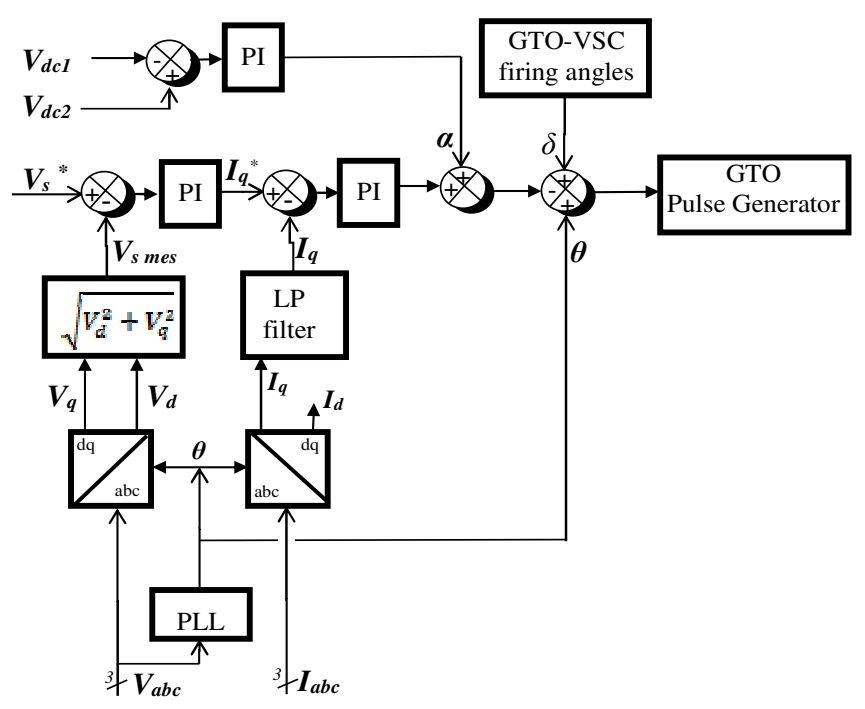

Fig. 4. Control scheme of the 48 pulse STATCOM

\section{SYSTEM CONFIGURATION}

The studied power system consists of two $400 \mathrm{MW}$ offshore wind farms and an islanded platform for the HVDC rectifier station, which comprises auxiliaries, ac filters and a STATCOM (fig. 5) [13].

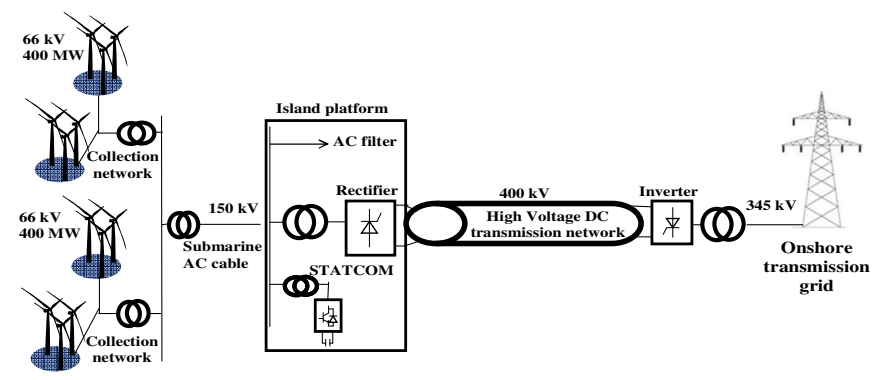

Fig. 5. HVDC transmission system with an AC export network

Each wind farm consists in $4 \mathrm{MW}$ turbines, which are gathered in clusters by an $\mathrm{AC} 66 \mathrm{kV}$ network. The voltage is rised up to $150 \mathrm{kV}$ in order to export the $\mathrm{AC}$ offshore power. A $300 \mathrm{~km}(400 \mathrm{kV}, 2 \mathrm{kA})$ LCC HVDC interconnection, with 12 pulse converters on both rectifier and inverter sides, is used to transmit power to the onshore network $(345 \mathrm{kV}, 50 \mathrm{~Hz})$. The submarine cable is modeled as a $\pi$ model with parameters coming from $\mathrm{ABB}$ datasheets [9] [10] and [2]. Filters and capacitive banks are connected on both sides to mitigate the 
harmonics and to supply reactive power. Also, smoothing reactors are connected in both rectifier and inverter side. The STATCOM based VSC is located at the rectifier side of the HVDC link.

\section{SIMULATION AND DISCUSSION OF RESULTS}

The modeling of the STATCOM in the studied power system is simulated by using the MATLAB/SIMULINK. In this study, the wind energy profile has arbitrary variable power (fig. 6) that will influence the operation of the network. Therefore the contribution of the STATCOM and the dynamic response will be seen under this scenario: The first $400 \mathrm{MW}$ wind power cluster is disturbed and the other cluster will deliver a constant $400 \mathrm{MW}$ power.

\section{A. System without a statcom}

The interaction between HVDC and AC system is investigated, the $\mathrm{SCR}$ is varied from a strong system $(\mathrm{SCR}=4)$ to a weak one $(\mathrm{SCR}=2.5)$ to see the effect of the weak and strong $\mathrm{AC}$ system on the LCC operation. The profile of generated wind power disturbance just in one collection of $400 \mathrm{MW}$ is shown in figure 6 .

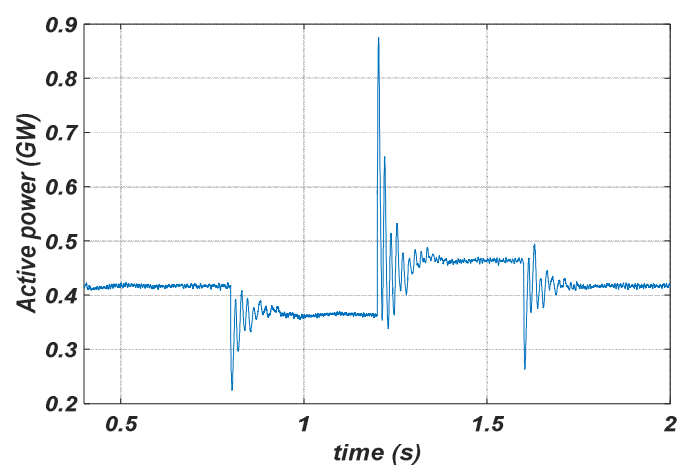

Fig. 6. Active power profile of $400 \mathrm{MW}$ collections

\section{1) AC Voltage and current at the rectifier side}

As it can be seen clearly in fig. 7, the voltage and the current at the rectifier side are not affected much in the case of a strong system $(S C R=4)$. However in the case of the weak side $(S C R=2.5)$. The obtained AC voltage and the current at the rectifier side have been affected by the variation of the generated wind power; At $t=1.2$, when the generated wind power reaches high values, the transient voltage on the rectifier side exceeds $1.6 \mathrm{pu}$ (60\% higher than the nominal value). This high transient voltage makes failure to the rectifier switching.
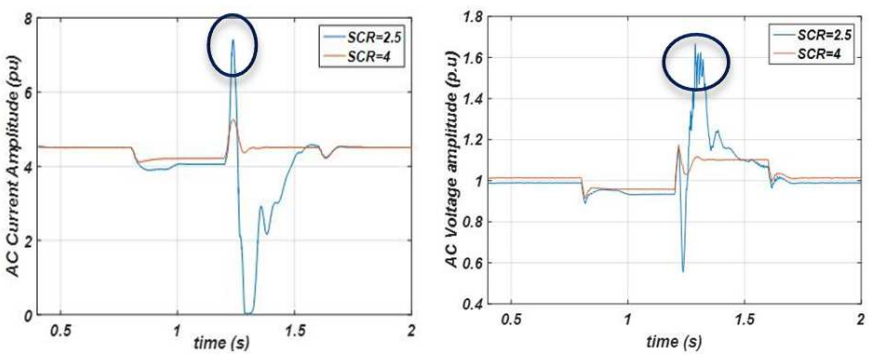

Fig. 7. AC current and voltage magnitude at rectifier side

\section{2) Commutation failure}

As shown in fig. 8, the plot of the rectifier valve thyristor current indicates a number of commutation failures of the valve groups ( 1 and 3 ) during the interval $t=1.2 \mathrm{~s}$ to $t=1.6 \mathrm{~s}$, which is caused by an increase in the DC current because the valves 1 and 3 are conducting simultaneously.

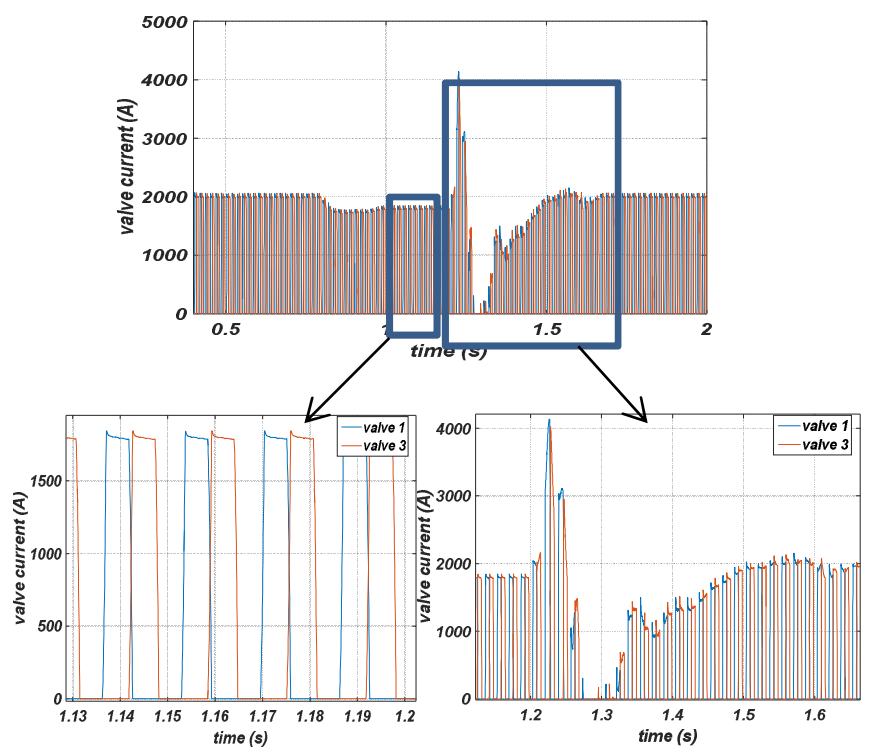

Fig. 8. Valve currents during a failed commutation

\section{3) DC voltage and current at the rectifier side}

When an overvoltage occurs at the rectifier side $(\mathrm{t}=1.2 \mathrm{~s})$, as it is illustrated in fig. 7, the DC current (fig. 9) increases to 2.1 pu and the DC voltage starts to fall to a low value at the rectifier side. This DC voltage drop is sensed by the Voltage Dependent Current Order Limiter (VDCOL). The VDCOL reduces the reference current to $0.35 \mathrm{pu}$ at the rectifier. A DC current still continue to circulate. Then, at $t=1.27 \mathrm{~s}$, after detecting a low DC voltage by the DC fault protection, the rectifier now operates in inverter mode. Since the DC line voltage becomes negative during a period following the commutation failures, no active power will be transmitted during this time and the energy stored in the line is returned to the $\mathrm{AC}$ system. Via the previous simulation results, some problems and difficulties hinder the good operation of the LCC system at a low SCR, therefore a STATCOM is needed to support the work of the LCC HVDC technology.
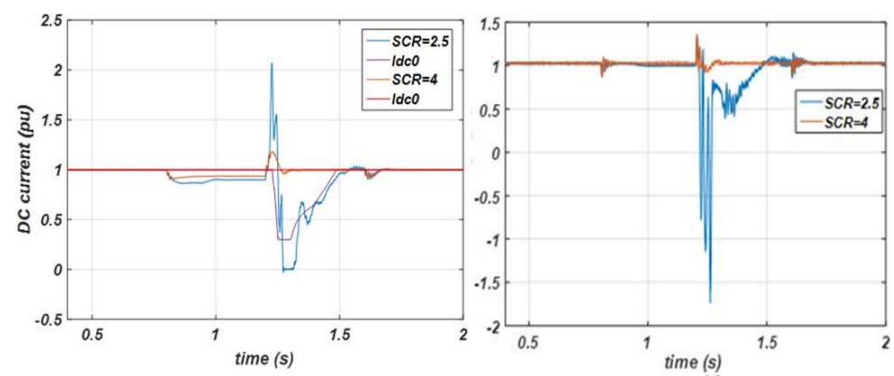

Fig. 9. DC current and voltage at rectifier side

\section{B. System with a statcom}

To overcome previous problems, a STATCOM is installed in the system to deliver and control the reactive power and therefore reduce voltage fluctuations. It is located at the rectifier side of the HVDC link and has a rating of $\pm 100 \mathrm{MVA}$. It consists of a three-level 48-pulse inverter and two series-connected 3000 $\mu \mathrm{F}$ capacitors. This work is related to the study of the 
STATCOM impact at a LCC HVDC rectifier connected to a weak AC offshore network with $S C R=2.5$.

\section{1) AC voltage and current at rectifier side}

Used parameters are $R_{t}=0.1 \Omega, L_{t}=1 \mathrm{mH}, C_{t}=0.55 \mu \mathrm{F}$. First, the effective operation of the model and of its control is tested. Then, different plausible scenarios for the isolated mode are simulated.

The STATCOM has a good impact on the rectifier side (fig. 10). At $t=1.2 \mathrm{~s}$ the transient ripple of the AC voltage does not exceed $1.19 \mathrm{pu}$, whereas without STATCOM, this transient exceeds $1.6 \mathrm{pu}$. Also, it can be observed that the AC current keeps conducting in normal condition (where the current becomes zero at $t=1.25 \mathrm{~s}$ in the absence of a STATCOM).

As shown in figure 11 the reference voltage $V O$ is set to 1.0 $\mathrm{pu}$, the STATCOM does not operate initially (zero current) from $t=0.4 \mathrm{~s}$ to $t=0.8 \mathrm{~s}$ and the DC voltage is maintained at $13 \mathrm{kV}$, which is a consequence of the constant wind power generated.

At $t=0.8 \mathrm{~s}$, the voltage is suddenly decreased by $20 \%$ from the nominal voltage $(0.8 \mathrm{pu})$, so Vmeas becomes lower than the reference voltage $V 0$, the voltage regulator will generate high reactive current to supply an extra capacitive reactive power. As it is shown in fig. 12, the STATCOM reacts by generating reactive power ( $Q=-85 \mathrm{Mvar}$ ) to keep the voltage at the rectifier side at $0.97 \mathrm{pu}$ (compared to $0.93 \mathrm{pu}$ without STATCOM). At this point, the DC voltage has increased to $15 \mathrm{kV}$ due to the reduction in generated power (fig. 13).
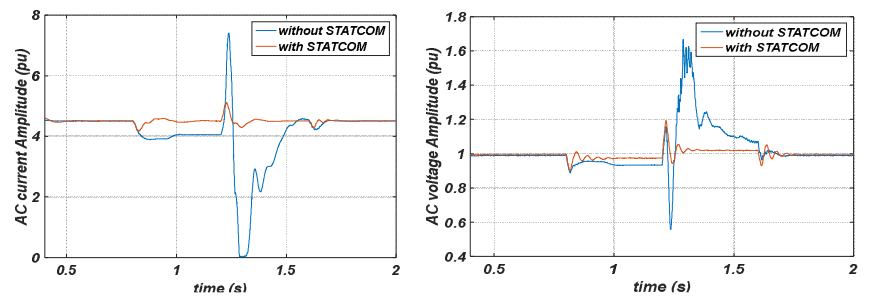

Fig. 10. AC current and voltage at rectifier side

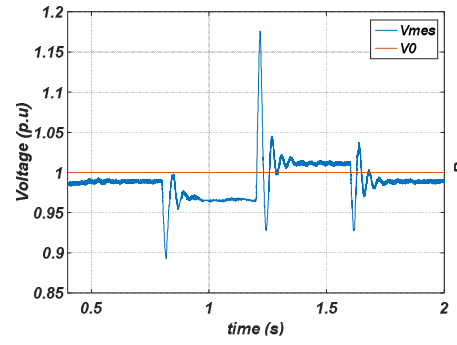

Fig. 11. Measured voltage at PCC

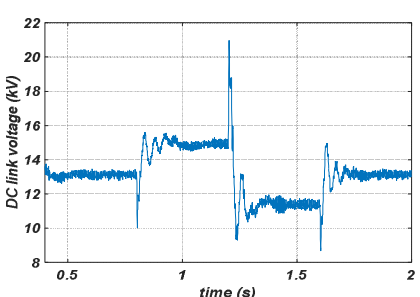

Fig. 13. DC Link Voltage

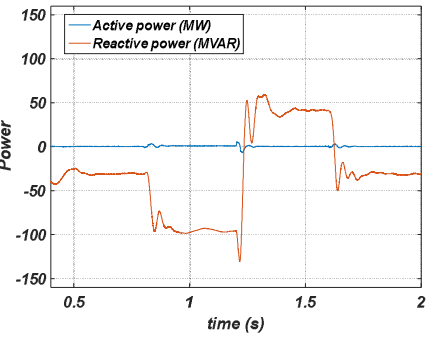

Fig. 12. Active and reactive power at the STATCOM side

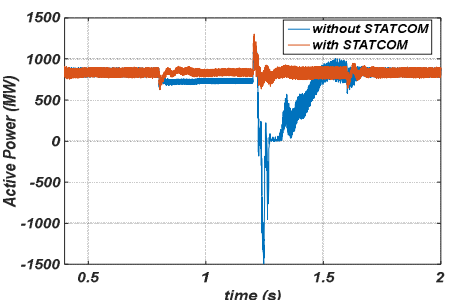

Fig. 14. Active power at the rectifier side
Then, at $t=1.2$ (s) the source voltage is increased to $1.2 \mathrm{pu}$ of its nominal value. The STATCOM reacts by changing its operating point from capacitive to inductive mode to keep the voltage at the rectifier side at $1.02 \mathrm{pu}$ (compared to $1.08 \mathrm{pu}$ without STATCOM). At this point the STATCOM absorbs 65 Mvar and the DC voltage has been decreased to $11.5 \mathrm{kV}$.

Finally, at $t=1.6 \mathrm{~s}$, and after some transients, the voltage source is set back to its nominal value, the STATCOM operating point comes back to zero Mvar and the STATCOM dc link voltage returns to its rated value.

\section{2) DC current and voltage at DC rectifier side}

The connection of a STATCOM to the power system enhanced the DC voltage and current at the rectifier DC side, as illustrated in fig. 15. The STATCOM kept the DC voltage at almost equals to 1 p.u with small ripples. Furthermore, the overvoltage at $t=1.2(\mathrm{~s})$ did not affect the voltage very much compared to the output without STATCOM and there is no negative DC voltage neither negative active power (fig. 14), so the converter always work as a rectifier. In addition to that, the recovery time is very fast. Those results confirm the huge importance and the good performance of a STATCOM during faults conditions.
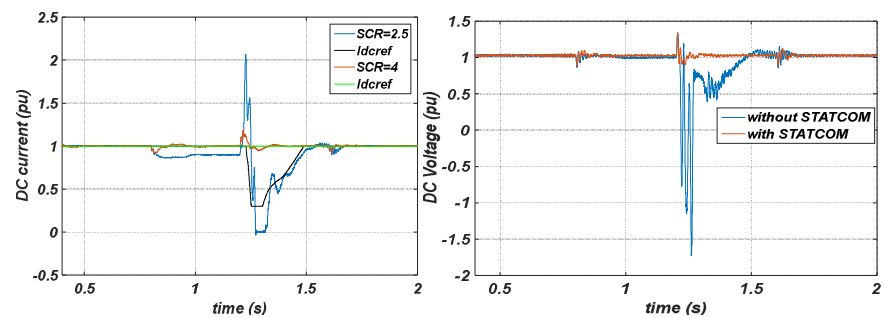

Fig. 15. DC voltage and current at the rectifier side

\section{3) Successful commutation:}

Contrary from the result obtained without using STATCOM, commutation failures are not observable in fig. 16. Again, the positive impact of the STATCOM is evident.

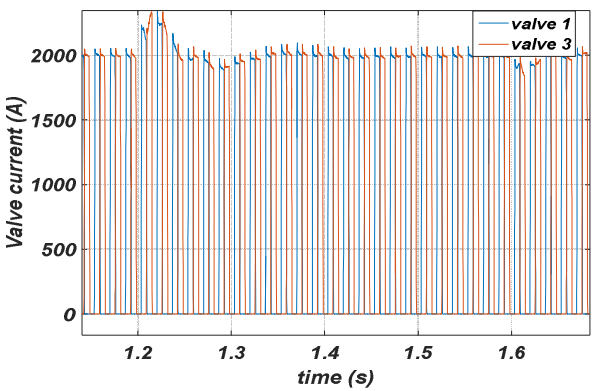

Fig. 16. Valve current during successful commutation

\section{POWER QUALITY}

\section{A. Power quality improvement}

$\mathrm{AC}$ and DC voltages and currents are affected by the variation of wind power (table 1). However, when the STATCOM is connected to the system; the power quality improvement can be noticed.

\section{TABLE I. POWER QUALITY INDEXES WITH AND WITHOUT STATCOM}

\begin{tabular}{|l|l|l|}
\hline & Without statcom & With statcom \\
\hline
\end{tabular}




\begin{tabular}{|c|c|c|}
\hline Max/Min AC voltage & $1.67 / 0.55$ (p.u) & $1.19 / 0.931$ (p.u) \\
\hline Max/Min AC current & $7.44 / 0$ (p.u) & $5.11 / 4.20$ (p.u) \\
\hline Max/Min DC voltage & $1.35 /-1.77$ (p.u) & $1.34 / 0.88$ (p.u) \\
\hline Max/Min DC current & $2.1 / 0$ (p.u) & $1.176 / 0.946$ (p.u) \\
\hline Transient time (s) & 1.55 & 1.33 \\
\hline
\end{tabular}

\section{B. Harmonic Compensation}

The STATCOM in harmonic compensation mode acts as an Active filter. From table 2, it is clear that the STATCOM mitigates the harmonics at the rectifier connection point; this will ensure a good power quality of the signals and prevent commutation failure.

TABLE II. THD MEASUREMENT IN \% AT DIFFERENT TIMES

\begin{tabular}{|c|c|c|c|c|c|}
\hline Time (s) & 1.2 & 1.3 & 1.4 & 1.5 & 1.6 \\
\hline With statcom & 8.18 & 1.61 & 1.33 & 1.12 & 6.45 \\
\hline Without statcom & 4.23 & 28.19 & 3.51 & 2.38 & 8.05 \\
\hline
\end{tabular}

\section{Analysis of the STATCOM sizing}

To investigate the influence of the capacitor sizing on the operating of the STATCOM, the transient overvoltage at the rectifier is recorded for different capacitance values. From the obtained characteristic (fig. 17), it seems that the overvoltage is decreased exponentially as the size of the DC capacitor $(\mathrm{Ca})$ increases. An exponential function that fits the different points is in the form of:

$$
F(C a)=a^{*} \exp \left(b^{*} C a\right)+c^{*} \exp \left(d^{*} C a\right)
$$

$$
a=0.08085 ; \quad b=-0.01788 ; \quad c=1.121 ; \quad d=-3.292 \mathrm{e}-06 \text {. }
$$

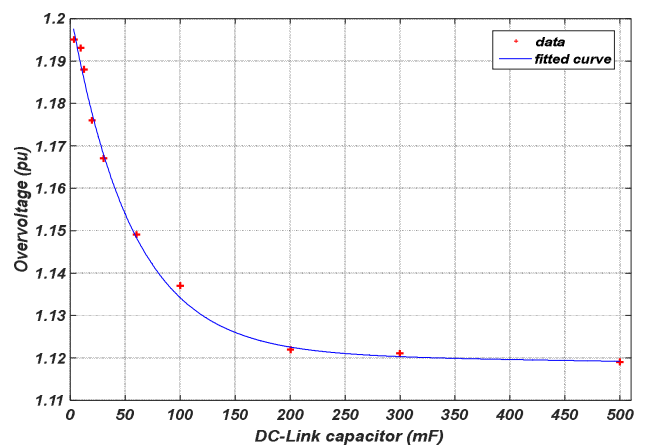

Fig. 17. Characteristic of the DC-link capacitance on the rectifier overvoltage with fitted curve

Moreover, table 3 illustrates the reduction of the capacitor size increases. The figure 18 shows the effect of the capacitor size on the DC link voltage, it can be seen clearly that the high transient voltage, at $\mathrm{t}=1.2 \mathrm{~s}$ in the case of small capacitor, is totally reduced when the capacitor value increases.

TABLE III. EFFECT OF DC CAPACITANCE ON TRANSIENT DC LINK VOLTAGE

\begin{tabular}{|c|c|c|}
\hline $\begin{array}{c}\text { DC capacitance } \\
\text { value in } \mu \mathrm{F}\end{array}$ & $\begin{array}{c}\text { Max transient } \\
\text { voltage in }(\mathrm{kV})\end{array}$ & $\begin{array}{c}\text { Min transient } \\
\text { voltage in }(\mathrm{kV})\end{array}$ \\
\hline 3000 & 21.04 & 9.02 \\
\hline 9000 & 20.24 & 9.14 \\
\hline 12000 & 19.76 & 9.43 \\
\hline 20000 & 18.98 & 9.94 \\
\hline 30000 & 18.31 & 10.08 \\
\hline 60000 & 17.38 & 10.37 \\
\hline 200000 & 15.74 & 10.46 \\
\hline
\end{tabular}

\section{CONCLUSION}

According to obtained simulation results, a STATCOM is a good solution for enhancing the power quality of the AC voltage and, so, the operation of a LCC connected to a weak AC networks. Finally, a good sizing of the STATCOM DC capacitor is essential to enable the effective decrease of transient overvoltages.

For future research, it is proposed to use a STATCOM Multi-level inverter with Pulse Width Modulation (PWM) technology based on the IGBT to the high-voltage transmission grid. This type has many advantages such as: harmonic reduction, reduce the size of the STATCOM, short response time

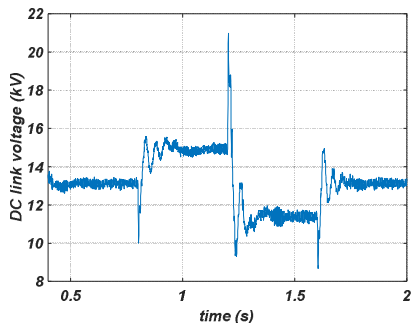

(a) $C=3000 \mu F$

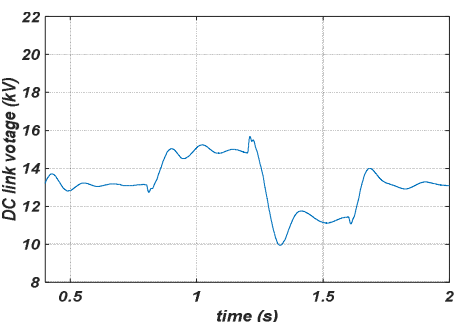

(b) $C=200000 \mu \mathrm{F}$
Fig. 18. DC voltage and current at rectifier side

\section{REFERENCES}

[1] S. Bozhko, R. V. Blasco-Gimenez, R. Li, J. Clare, and G. Asher, "Control of offshore DFIG-based wind farm grid with line-commutated HVDC connection,’'IEEE Trans. Energy Convers., vol. 22, no. 1, pp. 71-78, Mar. 2007

[2] A. P. Roses and B. Francois, " Practical determination of HVAC-HVDC Hybridization ratio for Offshore Transmission network Architectures through technico-economic considerations", IFAC Papers, vol. 49, no. 27, pp. 425-432, 2016.

[3] W. Li, L. Shi, L. Yao, Y. Zhao, Z. Jian and Y. Ni, "Comparison of HVAC and HVDC based grid integration on wind farm", IEEE power System Technology, International Conference on, October 2014.

[4] O.E.Oni,I.E.Davidson,andK.N.I.Mbangula,"A review of lcc-hvdc and vsc-hvdc technologies and applications", in 2016 IEEE 16th International Conference on Environment and Electrical Engineering (EEEIC), pp.1-7, June 2016.

[5] P. Fischer de Toledo, "Modelling and control of a line-commutated HVDC transmission system interacting with a VSC STATCOM," Ph.D. dissertation, Royal Inst. Technol., Stockholm, Sweden, 2007.

[6] D. Jovcic and K. Ahmed, "High-Voltage Direct Current Transmission: Converters Systems and DC Grids", John Wiley \& Sons, ISBN 978-1118-84666-7, 2015.

[7] O. Bouhali, "Contribution des convertisseurs multi-niveauxau raccordement de la production d'origine éolienne sur un réseau électrique", PhD. Thesis, Ecole Centrale de Lille and Ecole Nationale Polytechnique, 2007.

[8] Z. Xi,"Control Strategies of STATCOM during System Faults", PhD. Thesis, North Carolina State University, 2013.

[9] ABB, "XLPE submarine cable systems -Attachment to XLPE land cable systems -User's guide", http://www04.abb.com/, 2010 (accessed 15.06.2017).

[10] ABB Group and others, XLPE Land Cable Systems User's Guide, 2006.

[11] B Francois, JP Hautier, "Design of a fault tolerant control system for a NPC multilevel inverter", Proc. IEEE International Symp. Industrial Electronics 2002, pp. 1075-1080.

[12] K. Shinoda, A. Benchaib, X. Guillaud, S. Bacha, B. Francois, "Modelling of a VSC-Based Multi-Terminal HVDC Network for Dynamic Stability Analysis", COMPEL - The international journal for computation and mathematics in electrical and electronic engineering, vol. 36, Iss. 1, pp. $240-257,2017$. 
2018 IEEE International Conference on Industrial Technology (ICIT), February 20-22, 2018, Lyon, France

[13] N. G. Kouassi, B. Francois, "AC Offshore Grid Forming of a Collector Network for Wind Park by Considering Storage and Hybrid Power Electronic Systems“, CISTEM conference, November 2016, Marrakech, Marroco. 